\title{
Characterization of the Rydberg Bonding in $\left(\mathrm{NH}_{4}\right)_{2}^{-}$
}

\author{
Robyn Barrios, Piotr Skurski, ${ }^{\dagger}$ and Jack Simons* \\ Henry Eyring Center for Theoretical Chemistry, Department of Chemistry, University of Utah, \\ Salt Lake City, Utah 84112
}

Received: April 6, 2000; In Final Form: August 28, 2000

\begin{abstract}
The Rydberg bonding in $\left(\mathrm{NH}_{4}\right)_{2}{ }^{-}$and in its neutral and cationic counterparts have been examined using ab initio electronic structure theory. Analogous calculations on $\mathrm{Li}_{2}{ }^{-}, \mathrm{Na}_{2}{ }^{-}$, and $\mathrm{K}_{2}{ }^{-}$and on their neutral molecules and cations have also been performed for comparison with the Rydberg bonding cases. The dissociation energy $D_{\mathrm{e}}$ for $\left(\mathrm{NH}_{4}\right)_{2}{ }^{-} \rightarrow \mathrm{NH}_{4}+\mathrm{NH}_{4}{ }^{-}$is found to be $4 \mathrm{kcal} \mathrm{mol}^{-1}$ at the highest level of theory used, while the corresponding $D_{\mathrm{e}}$ 's for the cation and the neutral molecule are 20 and $9 \mathrm{kcal} \mathrm{mol}^{-1}$, respectively. The vertical electron detachment energy of $\left(\mathrm{NH}_{4}\right)_{2}{ }^{-}$is predicted to be $0.46 \mathrm{eV}$, which is nearly the same as that of $\mathrm{NH}_{4}{ }^{-}$. The trends in the interfragment equilibrium distances $R_{\mathrm{e}}$, the harmonic vibrational frequencies $\omega$, and the dissociation energies within alkali dimers, $\mathrm{NH}_{4}$ dimers, and their respective anions and cations have been examined and are discussed.
\end{abstract}

\section{Introduction}

The ammonium cation $\mathrm{NH}_{4}{ }^{+}$is a closed-shell species which is known ${ }^{1}$ to produce, upon electron attachment, a neutral $\mathrm{NH}_{4}$ that is thermodynamically unstable with respect to $\mathrm{NH}_{3}+\mathrm{H}$ and has its outermost electron in a Rydberg orbital, as shown in Figure 1. The attachment of another electron to $\mathrm{NH}_{4}$ produces the so-called double-Rydberg anion ${ }^{2} \mathrm{NH}_{4}{ }^{-}$, which has its two outermost electrons occupying Rydberg orbitals. This anion is electronically stable by ca. $0.4 \mathrm{eV}$ relative to $\mathrm{NH}_{4}+\mathrm{e}^{-}$but thermodynamically unstable with respect to $\mathrm{NH}_{3}+\mathrm{H}^{-}$.

In earlier efforts, the geometries, vibrational frequencies, and chemical bonding properties of $\mathrm{NH}_{4}, \mathrm{NH}_{4}{ }^{-}$, and other species containing electrons in Rydberg orbitals have been characterized using ab initio electronic structure theory. We also examined the possibility that chemical bonds can be formed ${ }^{3}$ when Rydberg orbitals on neighboring fragments overlap. For example, we studied the bonding that arises when two $\mathrm{NH}_{4}$ neutral molecules combine to form $\left(\mathrm{NH}_{4}\right)_{2}$, with two electrons occupying a bonding Rydberg molecular orbital (mo), as shown in Figures 1 and 2. We also considered the bonding in the corresponding cation $\left(\mathrm{NH}_{4}\right)_{2}{ }^{+}$with only one electron in the bonding Rydberg mo and found that the dissociation energy $\left(D_{\mathrm{e}}\right)$ of $\left(\mathrm{NH}_{4}\right)_{2}{ }^{+} \rightarrow \mathrm{NH}_{4}+\mathrm{NH}_{4}{ }^{+}$is considerably larger than the dissociation energy of the neutral $\left(\mathrm{NH}_{4}\right)_{2} \rightarrow \mathrm{NH}_{4}+\mathrm{NH}_{4}$ even though the neutral molecule nominally has two electrons in the bonding Rydberg mo whereas the cation has only one such electron. ${ }^{4}$

None of the species we investigated has its antibonding Rydberg orbital occupied. Therefore, we decided to delve deeper into the nature of Rydberg bonding by probing how $D_{\mathrm{e}}$ and the interfragment vibrational frequency and geometry depend on the number of Rydberg electrons. In the present study, we consider the anion $\left(\mathrm{NH}_{4}\right)_{2}{ }^{-}$, in which two electrons occupy the bonding Rydberg mo and one electron occupies the antibonding Rydberg mo (shown in Figure 2). We also examine the bonding (characterized via bond lengths, harmonic vibrational frequen-

$\dagger$ Permanent address: Department of Chemistry, University of Gdansk, 80-952 Gdansk, Poland.
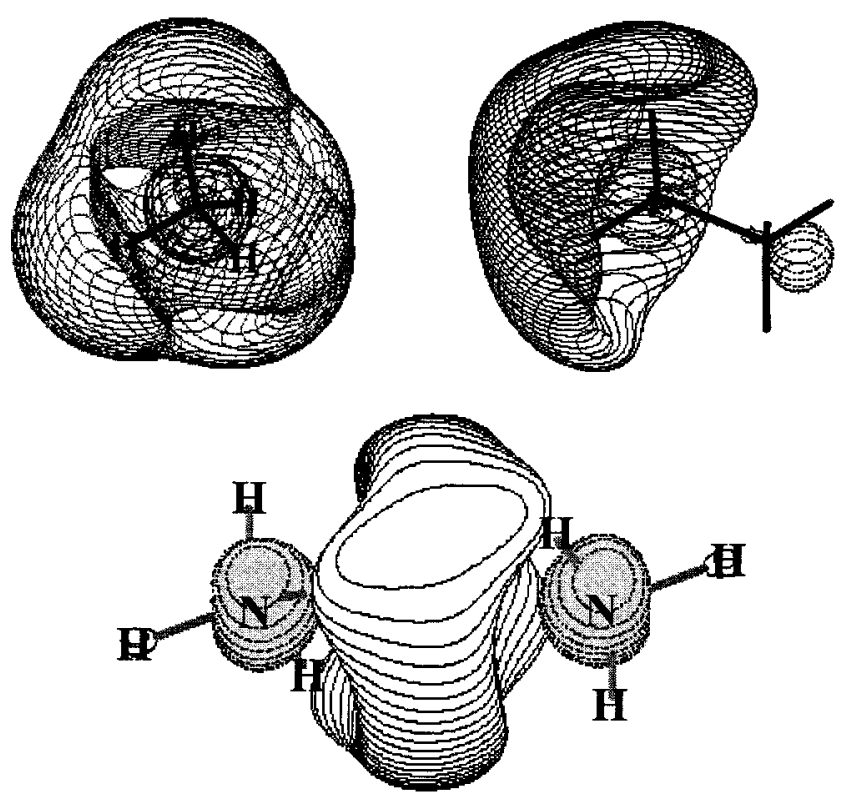

Figure 1. Rydberg orbital of $\mathrm{NH}_{4}$ (left) and $\mathrm{H}_{3} \mathrm{C}-\mathrm{NH}_{3}$ (right) and the Rydberg bonding orbital of $\left(\mathrm{NH}_{4}\right)_{2}^{+}$(bottom).

cies or force constants, and dissociation energies) in several alkali dimer cations, neutral molecules, and anions, which we view as analogues to our Rydberg-bound $\left(\mathrm{NH}_{4}\right)_{2}$ species because they contain one, two, or three electrons in bonding or antibonding mos formed from their outermost valence s orbitals. By comparing the trends seen in the neutral and charged alkali species to what we find in $\left(\mathrm{NH}_{4}\right)_{2}{ }^{+},\left(\mathrm{NH}_{4}\right)_{2}$, and $\left(\mathrm{NH}_{4}\right)_{2}{ }^{-}$, we shed further light on the nature of the Rydberg bond.

\section{Methods}

The equilibrium geometries of the cationic, neutral molecule, and anionic species were optimized and their harmonic vibrational frequencies calculated at the second-order Møller-Plesset (MP2) perturbation level of theory ${ }^{5}$. In all calculations, the values of $\left\langle S^{2}\right\rangle$ never exceeded 0.7508 (after annihilation) for 

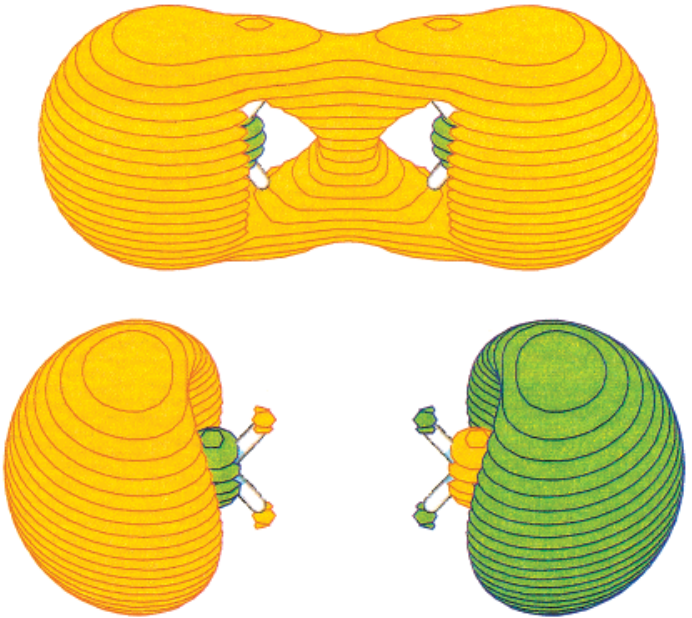

Figure 2. Rydberg bonding (top) and antibonding (bottom) orbitals in $\left(\mathrm{NH}_{4}\right)_{2}^{-}$.

doublet states, so we are confident that spin-contamination effects are negligible. The electron binding energies were studied at the Koopmans' theorem (KT), ${ }^{6} \mathrm{SCF}, \mathrm{MP} n(n=2-4)$, and coupled-cluster $(\mathrm{CCSD}(\mathrm{T}))$ levels. The dissociation energies for the charged and neutral $\mathrm{NH}_{4}$ dimers were also studied at the SCF, MPn, and CCSD(T) levels, and the basis set superposition errors (BSSE) were removed as described in ref 7. All calculations were performed with the GAUSSIAN 98 program $^{8}$ on $500 \mathrm{MHz}$ dual processor Intel Pentium III computers on an SGI Origin2000 numerical server. The three-dimensional plots of molecular orbitals were generated with the MOLDEN program. ${ }^{9}$

The choice of the atomic orbital basis sets describing the cationic molecules and additional bound electrons is very important for producing reliable geometries, frequencies, and dissociation energies. They must be flexible enough to describe the static charge distribution of the cationic molecular host, allow for the polarization and dispersion stabilization of the neutral molecule and anion upon electron attachment, and properly describe the Rydberg bonds. To describe the fundamental valence orbitals, we carried out calculations with the $6-311++\mathrm{G}^{* *}$ basis set. ${ }^{10}$ This constitutes the fundamental valence bases for our calculations both on $\left(\mathrm{NH}_{4}\right)_{2}$ and its ions and on alkali dimers and their ions. We employed the $6-311++\mathrm{G}^{* *}$ basis because it has been proven reliable in previous studies on $\left(\mathrm{NH}_{4}\right)_{2}$.

Following the procedure we used had in an earlier study on Rydberg and dipole-bound species, we supplemented the valence basis sets with extra diffuse functions having very low exponents, which are necessary to properly describe the Rydberg orbitals and resulting Rydberg bonding and antibonding mos. In particular, we supplemented the valence basis sets with extra even-tempered ${ }^{11}$ three-term $s$ and $p$ sets of diffuse functions centered on both the $\mathrm{N}$ atoms. We started to build up the exponents of these diffuse functions from the lowest $s$ and $p$ exponents included in the nitrogen valence basis set, and we used a geometric progression ratio of 3.2 based on our earlier experience in designing bases for Rydberg species. ${ }^{12}$ As a result, the extra diffuse $s$ and $p$ functions share exponent values and have the lowest exponent of $1.950070 \times 10^{-3}$ au for $s$ and $p$ symmetries.

We verified that the MP2 electron binding energy of the parent $\mathrm{NH}_{4}{ }^{-}$anion, which has been studied both theoretically and experimentally, ${ }^{13}$ changes by $<0.0005 \mathrm{eV}$ if one more set of $s$ and $p$ diffuse functions is added to the basis. Also, when

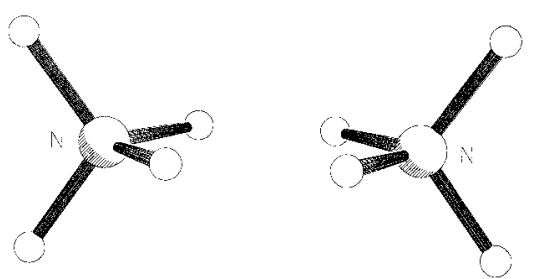

Figure 3. Equilibrium structure of $\left(\mathrm{NH}_{4}\right)_{2}{ }^{-}$.

TABLE 1: Bond Energies (kcal mol ${ }^{-1}$ ) and N-N Distances (A, MP2 Level) for Cationic, Neutral, and Anionic $\mathbf{N H}_{4}$ Dimers

\begin{tabular}{lccc}
\hline & \multicolumn{3}{c}{$6-311++\mathrm{G}^{* *+3}(\mathrm{sp})$} \\
\cline { 2 - 4 } & $\left(\mathrm{NH}_{4}\right)_{2}{ }^{+}$ & $\left(\mathrm{NH}_{4}\right)_{2}$ & $\left(\mathrm{NH}_{4}\right)_{2}{ }^{-}$ \\
\hline SCF & 19.2 & -5.2 & 7.0 \\
MP2 & 20.7 & 8.6 & 9.4 \\
MP3 & 20.4 & 9.1 & 8.6 \\
MP4 & 20.5 & 10.9 & 7.0 \\
CCSD(T) & 20.4 & 10.7 & 9.8 \\
CCSD(T) $+\Delta \mathrm{ZPE}^{a}$ & 20.3 & 9.2 & 4.2 \\
CCSD(T) ${ }^{b}+\Delta \mathrm{ZPE}$ & 20.1 & 8.6 & 3.8 \\
$R_{\mathrm{e}}$ & 4.48 & 3.65 & 4.22
\end{tabular}

${ }^{a} \triangle \mathrm{ZPE}$ denotes zero-point energy correction. ${ }^{b}$ Denotes basis set superposition correction (all BSSE corrections were $<1 \mathrm{kcal} \mathrm{mol}^{-1}$ ).

a set of diffuse functions possessing $d$ symmetry is added to our basis, the electron binding energy remains approximately the same. Moreover, we verified that the electron binding energy of the anionic dimer changes by only ca. $0.019 \mathrm{eV}$ upon the addition of two s, two $\mathrm{p}$, and three d diffuse basis functions when calculated at the $\operatorname{CCSD}(\mathrm{T})$ level. As a result, we feel confident that the extra diffuse $\mathrm{s}$ and $\mathrm{p}$ basis functions are adequate for describing the neutral $\mathrm{NH}_{4}$ and $\left(\mathrm{NH}_{4}\right)_{2}$ and their anions.

Our calculations on the alkali dimers and their ions were performed using the same methods (i.e., basis sets and methods for treating electron correlation) we had used on the Rydberg species. These data on the alkalis are not meant to represent more accurate data than are currently available from experimental or theoretical sources. Instead, they represent the $D_{\mathrm{e}}$, $\omega_{\mathrm{e}}$, and $R_{\mathrm{e}}$ values that are most comparable to those we achieved for the Rydberg molecules because they were obtained using the same tools used on the Rydberg systems. In tabulating our findings on the alkali dimers and their ions, we compare our calculated $D_{\mathrm{e}}, \omega_{\mathrm{e}}$, and $R_{\mathrm{e}}$ values to the data obtained through other (experimental and theoretical) means, and we find our data to be in line with the earlier observations.

\section{Results}

A. Equilibrium Geometries. Figure 3 shows the equilibrium structure of $\left(\mathrm{NH}_{4}\right)_{2}{ }^{-}$, and Table 1 gives the $\mathrm{N}-\mathrm{N}$ distances $\left(R_{\mathrm{e}}\right)$ calculated at the MP2 level of the cation, anion, and neutral molecule. ${ }^{14}$ We note that $R_{\mathrm{e}}$ decreases from the cation to the neutral molecule and then increases from the neutral molecule to the anion, which is in line with the Rydberg-bond orders of the cation, neutral molecule, and anionic species (these bond orders are $1 / 2,1$, and $1 / 2$, respectively).

B. Vibrational Frequencies of $\mathbf{N H}_{\mathbf{4}}$ Dimer Species. All 24 harmonic frequencies for the cation, neutral molecule, and anion are given in Table 2. Because the internal geometries (i.e., $\mathrm{N}-\mathrm{H}$ bond lengths and angles) do not vary substantially among these three species, most of the variation in the $\left(\mathrm{NH}_{4}\right)_{\ldots} \ldots\left(\mathrm{NH}_{4}\right)$ interfragment vibrational frequency (shown in bold in Table 2) should be due to variations in the corresponding force constants. 
TABLE 2: Harmonic Frequencies for Cationic, Neutral, and Anionic $\mathrm{NH}_{4}$ Dimers $\left(\mathrm{cm}^{-1}\right)$

\begin{tabular}{lll}
\hline & $\left.6-311++\mathrm{G}^{* *+3}+3 \mathrm{sp}\right)$ & \\
\hline$\left(\mathrm{NH}_{4}\right)_{2}{ }^{+}$ & $\left(\mathrm{NH}_{4}\right)_{2}$ & $\left(\mathrm{NH}_{4}\right)_{2}{ }^{-}$ \\
\hline $16 \mathrm{a}_{1 \mathrm{u}}$ & $70 \mathrm{a}_{\mathrm{u}}$ & $25 \mathrm{a}_{\mathrm{g}}$ \\
$\mathbf{1 2 7} \mathrm{a}_{1 \mathrm{~g}}$ & $79 \mathrm{~b}_{\mathrm{u}}$ & $41 \mathrm{a}_{\mathrm{u}}$ \\
$128 \mathrm{e}_{\mathrm{g}}$ & $\mathbf{1 1 0} \mathrm{a}_{\mathrm{g}}$ & $69 \mathrm{~b}_{\mathrm{u}}$ \\
$128 \mathrm{e}_{\mathrm{g}}$ & $140 \mathrm{a}_{\mathrm{u}}$ & $\mathbf{8 5} \mathrm{a}_{\mathrm{g}}$ \\
$190 \mathrm{e}_{\mathrm{u}}$ & $164 \mathrm{a}_{\mathrm{g}}$ & $115 \mathrm{~b}_{\mathrm{g}}$ \\
$190 \mathrm{e}_{\mathrm{u}}$ & $218 \mathrm{~b}_{\mathrm{g}}$ & $352 \mathrm{a}_{\mathrm{u}}$ \\
$1368 \mathrm{e}_{\mathrm{u}}$ & $1343 \mathrm{~b}_{\mathrm{g}}$ & $1342 \mathrm{~b}_{\mathrm{g}}$ \\
$1368 \mathrm{e}_{\mathrm{u}}$ & $1346 \mathrm{a}_{\mathrm{u}}$ & $1353 \mathrm{a}_{\mathrm{g}}$ \\
$1400 \mathrm{a}_{1 \mathrm{~g}}$ & $1351 \mathrm{a}_{\mathrm{g}}$ & $1376 \mathrm{~b}_{\mathrm{u}}$ \\
$1406 \mathrm{a}_{2 \mathrm{u}}$ & $1351 \mathrm{~b}_{\mathrm{u}}$ & $1376 \mathrm{a}_{\mathrm{g}}$ \\
$1432 \mathrm{e}_{\mathrm{g}}$ & $1367 \mathrm{a}_{\mathrm{g}}$ & $1491 \mathrm{~b}_{\mathrm{u}}$ \\
$1432 \mathrm{e}_{\mathrm{g}}$ & $1416 \mathrm{~b}_{\mathrm{u}}$ & $1587 \mathrm{~b}_{\mathrm{u}}$ \\
$1652 \mathrm{e}_{\mathrm{u}}$ & $1591 \mathrm{a}_{\mathrm{u}}$ & $1594 \mathrm{a}_{\mathrm{g}}$ \\
$1652 \mathrm{e}_{\mathrm{u}}$ & $1603 \mathrm{~b}_{\mathrm{u}}$ & $1605 \mathrm{~b}_{\mathrm{g}}$ \\
$1659 \mathrm{e}_{\mathrm{g}}$ & $1608 \mathrm{~b}_{\mathrm{g}}$ & $1607 \mathrm{a}_{\mathrm{u}}$ \\
$1659 \mathrm{e}_{\mathrm{g}}$ & $1625 \mathrm{a}_{\mathrm{g}}$ & $1998 \mathrm{a}_{\mathrm{u}}$ \\
$2485 \mathrm{a}_{1 \mathrm{~g}}$ & $3014 \mathrm{~b}_{\mathrm{u}}$ & $3019 \mathrm{~b}_{\mathrm{u}}$ \\
$2579 \mathrm{a}_{2 \mathrm{u}}$ & $3042 \mathrm{a}_{\mathrm{u}}$ & $3063 \mathrm{ag}$ \\
$3392 \mathrm{a}_{1 \mathrm{~g}}$ & $3044 \mathrm{a}_{\mathrm{g}}$ & $3186 \mathrm{ag}_{\mathrm{g}}$ \\
$3398 \mathrm{a}_{2 \mathrm{u}}$ & $3091 \mathrm{~b}_{\mathrm{g}}$ & $3192 \mathrm{ag}$ \\
$3537 \mathrm{e}_{\mathrm{g}}$ & $3211 \mathrm{~b}_{\mathrm{u}}$ & $3203 \mathrm{~b}_{\mathrm{g}}$ \\
$3537 \mathrm{e}_{\mathrm{g}}$ & $3212 \mathrm{a}_{\mathrm{g}}$ & $3206 \mathrm{~b}_{\mathrm{u}}$ \\
$3538 \mathrm{e}_{\mathrm{u}}$ & $3287 \mathrm{a}_{\mathrm{g}}$ & $3206 \mathrm{~b}_{\mathrm{u}}$ \\
$3538 \mathrm{e}_{\mathrm{u}}$ & $3295 \mathrm{~b}_{\mathrm{u}}$ & $5484 \mathrm{a}_{\mathrm{u}}$ \\
\hline
\end{tabular}

We computed these force constants $(k)$ and found them to have the ratio of 2.2:1.7:1.0 for the cation, neutral molecule, and anion, which is indeed close to the ratio of the squares of the harmonic frequencies in Table 2 (shown in bold). These trends in $k$ (or $\omega$ ) do not follow the nominal Rydberg bond orders, in contrast to the trends in $R_{\mathrm{e}}$, which, for the cation, neutral molecule, and anion are 4.5, 3.6, and 4.2 $\AA$, respectively.

C. Rydberg Bond Dissociation Energies of $\mathbf{N H}_{\mathbf{4}}$ Dimers. The energies $\left(D_{\mathrm{e}}\right)$ needed to break the Rydberg bonding in the cation, neutral molecule, and anion are shown in Table 1, and they are 20,9 , and $4 \mathrm{kcal} \mathrm{mol}^{-1}$, respectively, computed at the highest level $(\operatorname{CCSD}(\mathrm{T}))$ and including the zero-point energies and the basis set superposition corrections $\left(<1 \mathrm{kcal} \mathrm{mol}^{-1}\right.$ in all cases). When comparing the trends in $D_{\mathrm{e}}$ to those in $R_{\mathrm{e}}, k$, and $\omega$, we noted significant differences. The trends in $R_{\mathrm{e}}(4.5$, 3.6, and $4.2 \AA$ ) do follow the progression in Rydberg bond orders, but the trends in $k, \omega\left(127,110,85 \mathrm{~cm}^{-1}\right)$, and $D_{\mathrm{e}}(20$, 9, $4 \mathrm{kcal} \mathrm{mol}^{-1}$ ) do not.

D. Comparison of $\mathbf{N H}_{4}$ Dimers with Selected Alkali Dimers. Our $\mathrm{NH}_{4}$ dimer and its ions are isoelectronic with the sodium dimer and its cation and anion, which contain a total of 22, 21, and 23 electrons, respectively. Of course, the sodium dimers employ valence 3 s orbitals to form their bonding and antibonding mos, whereas the $\mathrm{NH}_{4}$ dimers use Rydberg orbitals. The $\mathrm{NH}_{4}$ Rydberg orbital is more diffuse than the $\mathrm{Na} 3 \mathrm{~s}$ orbital (reflected by its lower ionization potential and electron affinity), so it is to be expected that overlap-induced bonding will be weaker in the $\mathrm{NH}_{4}$ dimer than in $\mathrm{Na}_{2}$. Nevertheless, to better understand the trends of $D_{\mathrm{e}}, k, \omega$, and $R_{\mathrm{e}}$ in our Rydberg-bound dimers, we carried out a series of calculations on several alkali dimers and their ions, aimed in particular at probing analogous trends in these species. We used the $6-311++\mathrm{G}^{* *+3}$ (sp) basis set again for $\mathrm{Na}_{2}{ }^{+}, \mathrm{Na}_{2}, \mathrm{Na}_{2}{ }^{-}$, and the $\mathrm{Li}$ and $\mathrm{K}$ counterparts, and we optimized the geometries for all species at the MP2 level. The resulting $R_{\mathrm{e}}, \omega$, and $D_{\mathrm{e}}$ values are shown in Table 3 along with data from Huber and Herzberg. ${ }^{15}$

In Figure 4 , the trends in $D_{\mathrm{e}}, R_{\mathrm{e}}$, and $\omega$ are summarized graphically, and the bond lengths $\left(R_{\mathrm{e}}\right)$ among the alkali dimers show trends (Figure 4b) consistent with expectations based on
TABLE 3: Bond Lengths (̊̊), Frequencies $\left(\mathrm{cm}^{-1}\right)$, and Energies (kcal mol ${ }^{-1}$ ) of Selected Alkali ${ }^{a}$ and $\mathrm{NH}_{4}$ Dimers

\begin{tabular}{lllc}
\hline dimer & \multicolumn{1}{c}{$R_{\mathrm{e}}$} & \multicolumn{1}{c}{$\omega_{\mathrm{e}}$} & $D_{\mathrm{e}}\left(6-311++\mathrm{G}^{* *}+3(\mathrm{sp})\right)$ \\
\hline $\mathrm{Li}_{2}{ }^{+}$ & 3.13 & 260 & $29.2(33.2)$ \\
$\mathrm{Li}_{2}$ & $2.74(2.67)$ & $342(351)$ & $22.8(24.1)$ \\
$\mathrm{Li}_{2}{ }^{-}$ & $3.18[3.1]$ & $212[230]$ & $18.3(20.3)[18]$ \\
$\mathrm{Na}_{2}{ }^{+}$ & $3.66(3.54)$ & $117(126)$ & $22.0(22.1)$ \\
$\mathrm{Na}_{2}$ & $3.12(3.08)$ & $161(159)$ & $15.9(16.6)$ \\
$\mathrm{Na}_{2}{ }^{-}$ & $3.61[3.6]$ & $93[99]$ & $13.5(10.1)[14]$ \\
$\mathrm{K}_{2}{ }^{-}$ & $4.58(4.11)$ & $71(67)$ & $17.4(19.6)$ \\
$\mathrm{K}_{2}$ & $3.91(3.91)$ & $92(92)$ & $9.7(11.85)$ \\
$\mathrm{K}_{2}{ }^{-}$ & 4.54 & 53 & 10.2 \\
$\mathrm{NH}_{4}{ }^{+}$ & 4.5 & 127 & 20 \\
$\mathrm{NH}_{4}$ & 3.6 & 110 & 9 \\
$\mathrm{NH}_{4}{ }^{-}$ & 4.2 & 85 & 4
\end{tabular}

${ }^{a}$ Values in parentheses are from ref 16 . Values in square brackets are from ref $15 \mathrm{C}$.
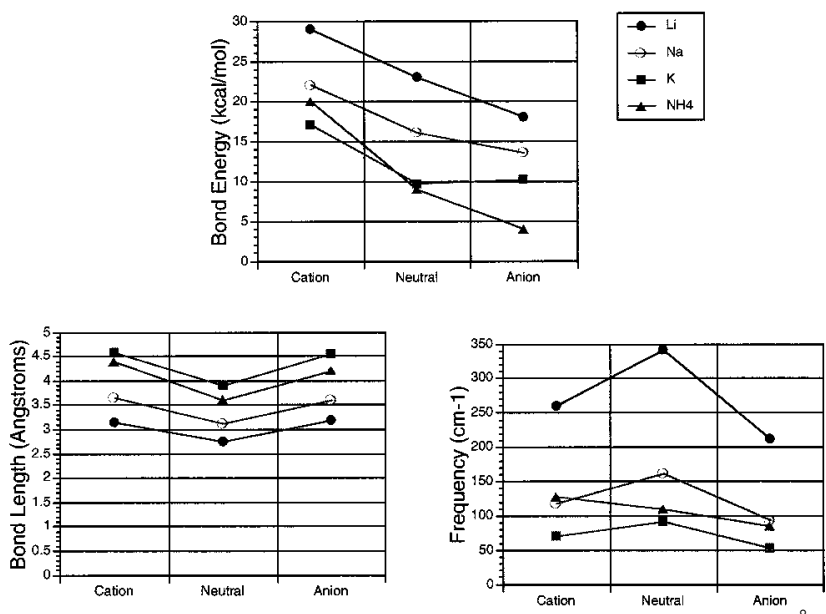

Figure 4. (a) Dissociation energies $\left(\mathrm{kcal} \mathrm{mol}^{-1}\right)$, (b) bond lengths $(\AA)$ (c) and harmonic vibrational frequencies $\left(\mathrm{cm}^{-1}\right)$ for the alkali and $\mathrm{NH}_{4}$ dimers.

bond order, similar to the trend in $\mathrm{NH}_{4}$ dimers. In contrast, the variation in $\omega$ among the alkali dimers again follows the nominal bond orders, but the $\omega$ values of the $\mathrm{NH}_{4}$ dimers deviate (see Figure $4 \mathrm{c}$ ). The trends in the $D_{\mathrm{e}}$ of alkali and $\mathrm{NH}_{4}$ dimers are shown in Figure 4a. In all cases, the values of $D_{\mathrm{e}}$ are largest for the cation, smaller for the neutral molecule, and smallest (except for $\mathrm{K}_{2}^{-}$) for the anion.

\section{Summary of Findings and Possible Interpretation of Trends}

The primary findings of this research are that (a) $\left(\mathrm{NH}_{4}\right)_{2}{ }^{-}$is bound relative to $\mathrm{NH}_{4}{ }^{-}+\mathrm{NH}_{4}$ by $4 \mathrm{kcal} \mathrm{mol}^{-1}$ at the highest level of theory employed, (b) $\left(\mathrm{NH}_{4}\right)_{2}{ }^{-}$is predicted to have a vertical electron detachment energy of $0.46 \mathrm{eV}$, (c) the geometry of $\left(\mathrm{NH}_{4}\right)_{2}{ }^{-}$is as described in Figure 3 and Table 1, and (d) the trends in $D_{\mathrm{e}}, R_{\mathrm{e}}$, and $\omega$ within the $\mathrm{NH}_{4}$ dimers are very similar to what is seen in the alkali dimers.

However, the data summarized in Figure 4 show that these trends do not track the nominal bond orders. We suggest that deviations from bond order trends in the alkalis and $\mathrm{NH}_{4}$ arise primarily from two sources: (a) electron repulsion among the two and three valence electrons of the neutral molecule and anion, respectively, and (b) additional attractive long-range charge-polarization interaction energies $-\alpha e^{2} / R^{4}$, which are absent for the neutral molecule but active for the cations and anions.

Let us elaborate on how we believe these two effects cause the bonding in the alkali and $\mathrm{NH}_{4}$ cases to deviate from the pattern of nominal bond orders. 
Because the valence orbitals of the alkalis and the Rydberg orbitals of $\mathrm{NH}_{4}$ are quite diffuse, their overlaps are small at the respective dimer equilibrium geometries. As a result, the overlap-induced contribution to the bonding arising from the attraction of the valence electron(s) to the two valence centers (i.e., the alkali cations or the $\mathrm{NH}_{4}{ }^{+}$) is not as large as that from conventional covalent bonds involving more electronegative elements. Indeed, it is well-known for the alkalis ${ }^{15}$ that there is very little buildup of electron density in the internuclear region when a bond is formed, which relates to the metallic behavior of these elements.

The weak overlap-induced bonding causes the effects of electron-electron repulsion to be relatively more important in such systems. Especially in the $\mathrm{NH}_{4}$ dimers considered here, electron repulsion gives rise to significant changes in the form of the Rydberg bonding and antibonding orbitals, depending on how many electrons occupy these orbitals. For example, the bonding orbital of the $\left(\mathrm{NH}_{4}\right)_{2}{ }^{+}$cation in Figure 1 differs substantially from the bonding orbital of the $\left(\mathrm{NH}_{4}\right)_{2}{ }^{-}$anion in Figure 2. In the cation, there is no (valence) electron repulsion, but in the anion, there are three electrons that repel; these differences cause the $\sigma$ and $\sigma^{*}$ orbitals of the cation and anion to be quite different.

We therefore suggest that these electron-electron $(\mathrm{e}-\mathrm{e})$ repulsion effects contribute to the trends in $D_{\mathrm{e}}$ values as follows: (a) For the alkali and Rydberg cations, where there is no valence $\mathrm{e}-\mathrm{e}$ repulsion, the bonding is dominated by overlap effects but is further enhanced by the additional $-\alpha e^{2} / R^{4}$ energy that must be overcome to effect dissociation.

(b) For the corresponding neutral molecules, there is $\mathrm{e}-\mathrm{e}$ repulsion between two $\sigma$ electrons in the $\sigma^{2}$ dimer, but the repulsion vanishes in the separated fragments (e.g., $\mathrm{Li}$ or $\mathrm{NH}_{4}$ ) where these two electrons are infinitely distant. As a result, the bond strength of the neutral molecule is diminished (relative to that of the cation) by this repulsion to more than offset the overlap-induced bonding of the neutral molecule's two $\left(\sigma^{2}\right)$ electrons. Moreover, there is no additional $-\alpha \mathrm{e}^{2} / \mathrm{R}^{4}$ energy required in this case. Hence, $D_{\mathrm{e}}$ is smaller in the neutral molecules than in the cations (see Figure 4a).

(c) For the anions, there is a $\mathrm{e}-\mathrm{e}$ repulsion among three electrons (two $\sigma$ 's and one $\sigma^{*}$ ) in the dimer that evolves into e-e repulsion between two electrons $\left(\sigma^{2}\right)$ in the anion fragment (e.g., $\mathrm{Li}^{-}$or $\mathrm{NH}_{4}{ }^{-}$). In addition, the $-\alpha e^{2} / R^{4}$ must be overcome to effect dissociation. However, the fact that $\mathrm{e}-\mathrm{e}$ repulsion is larger in the anion dimers than in their fragments combines with the antibonding character of the $\sigma^{*}$ orbital, which is now occupied, to reduce $D_{\mathrm{e}}$ beyond that of the neutral molecule (Figure 4a).

Acknowledgment. R.B. thanks Dr. S. Rudolph and Mr. D. Tate for their support. This work was supported by NSF Grants CHE9618904 and CHE9982420 to J.S. Domputer time was provided by the Center for High Performance Computing at the University of Utah. The University of Utah ACCESS Program provided partial support to R.B.

\section{References and Notes}

(1) (a) Herzberg, G. Faraday Discuss. Chem. Soc. 1981, 71, 165. (b) Gellene, G. I.; Cleary, D. A.; Porter, R. J. Chem. Phys. 1982, 77, 3471. (c) Harviliak, S.; King, H. F. J. Am. Chem. Soc. 1983, 105, 4. (d) Raynor, S.;
Herschbach, D. R. J. Phys. Chem. 1982, 86, 3592. (e) McMaster, B. N.; Mrozek, J.; Smith, V. H., Jr. Chem. Phys. 1982, 73, 131. (f) Cardy, H.; Liotard, D.; Dargelos, A.; Poquet, E. Chem. Phys. 1983, 77, 287. (g) Kassab, E.; Evleth, E. M. J. Am. Chem. Soc. 1987, 109, 1653. (h) Wang, J.; Boyd, R. Can. J. Phys. 1994, 72, 851.

(2) (a) Bowen, K. H.; Eaton, J. G. In The Structure of Small Molecules and Ions; Naaman, R., Vager, Z., Eds.; Plenum Press: New York, 1987; p 147. (b) Arnold, S. T.; Eaton, J. G.; Patel-Misra, D.; Sarkas, H. W.; Bowen, K. H. In Ion and Cluster Ion Spectroscopy and Structure; Maier, J. P., Ed.; Elsevier: Amsterdam, 1989. (c) Snodgrass, J. T.; Coe, J. V.; Freidhoff, C. B.; McHugh, K. M.; Bowen, K. H. Faraday Discuss. Chem. Soc. 1988, 86, 241. (d) Ortiz, J. V. J. Chem. Phys. 1987, 87, 3557. (e) Ortiz, J. V. J. Chem. Phys. 1990, 94, 4762. (f) Kalcher, J.; Rosmus, P.; Quack, M. Can. J. Phys. 1984, 62, 1323. (g) Cardy, H.; Larrieu, C.; Dargelos, A. Chem. Phys. Lett. 1986, 131, 507. (h) Cremer, D.; Kraka, E. J. Phys. Chem. 1986 90, 33. (i) Gutowski, M.; Taylor, H.; Hernandez, R.; Simons, J. J. Phys. Chem. 1988, 92, 6179. (j) Gutowski, M.; Simons, J. J. Chem. Phys. 1990, 93, 3874 .

(3) (a) Boldyrev, A. I.; Simons, J. J. Phys. Chem. 1992, 96, 8840. (b) Boldyrev, A. I.; Simons, J. J. Phys. Chem. A 1999, 103, 3575. (c) Wright, J. S.; McKay, D. J. Phys. Chem. 1996, 100, 7392. (d) Weikert, H. G.; Cederbaum, L. S.; Tarantelli, F.; Boldyrev, A. I. Z. Phys. D 1991, 18, 299.

(4) It should be noted, as Wright et al. showed, ${ }^{3}$ that the neutral $\left(\mathrm{NH}_{4}\right)_{2}$ is metastable against fragmenting to $\mathrm{H}_{2}+2 \mathrm{NH}_{3}$ and has a low dissociation barrier in this channel. On the other hand, the cation $\left(\mathrm{NH}_{4}\right)_{2}{ }^{+}$is stable with respect to $\mathrm{H}_{2}+\mathrm{NH}_{3}+\mathrm{NH}_{3}{ }^{+}$. In the present investigation, our goal is to characterize and understand the strength and nature of the Rydberg bond, so we restrict our attention to the dissociation of $\left(\mathrm{NH}_{4}\right)_{2}$ into $2 \mathrm{NH}_{4},\left(\mathrm{NH}_{4}\right)_{2}{ }^{+}$ into $\mathrm{NH}_{4}+\mathrm{NH}_{4}{ }^{+}$, and $\left(\mathrm{NH}_{4}\right)_{2}{ }^{-}$into $\mathrm{NH}_{4}+\mathrm{NH}_{4}{ }^{-}$because these dissociation energies, although not necessarily the lowest in each case, reflect the Rydberg bond strength.

(5) Møller, C.; Plesset, M. S. Phys. Rev. 1934, 46, 618.

(6) Koopmans, T. Physica (Amsterdam) 1934, 1, 104

(7) Chalasinski, G.; Gutowski, M. Chem. Rev. 1988, 88, 943.

(8) Frisch, M. J.; Trucks, G. W.; Schlegel, H. B.; Scuseria, G. E.; Robb, M. A.; Cheeseman, J. R.; Zakrzewski, V. G.; Montgomery, J. A., Jr.; Stratmann, R. E.; Burant, J. C.; Dapprich, S.; Millam, J. M.; Daniels, A. D.; Kudin, K. N.; Strain, M. C.; Farkas, O.; Tomasi, J.; Barone, V.; Cossi, M.; Cammi, R.; Mennucci, B.; Pomelli, C.; Adamo, C.; Clifford, S.; Ochterski, J.; Petersson, G. A.; Ayala, P. Y.; Cui, Q.; Morokuma, K.; Malick, D. K.; Rabuck, A. D.; Raghavachari, K.; Foresman, J. B.; Cioslowski, J.; Ortiz, J. V.; Stefanov, B. B.; Liu, G.; Liashenko, A.; Piskorz, P.; Komaromi, I.; Gomperts, R.; Martin, R. L.; Fox, D. J.; Keith, T.; Al-Laham, M. A.; Peng, C. Y.; Nanayakkara, A.; Gonzalez, C.; Challacombe, M.; Gill, P. M. W.; Johnson, B.; Chen, W.; Wong, M. W.; Andres, J. L.; Gonzalez, C.; Head-Gordon, M.; Replogle, E. S.; Pople, J. A. Gaussian 98, Revision A.7; Gaussian, Inc.: Pittsburgh, PA, 1998.

(9) Schaftenaar, G.; Noordik, J. H. J. Comput.-Aided Mol. Des. 2000 14,123

(10) (a) Ditchfield, R.; Hehre, W. J.; Pople, J. A. J. Chem. Phys. 1971, 54, 724. (b) Hehre, W. J.; Ditchfield, R.; Pople, J. A. J. Chem. Phys. 1972, 56, 2257. (c) Hariharan, P. C.; Pople, J. A. Mol. Phys. 1974, 27, 209. (d) Gordon, M. S. Chem. Phys. Lett. 1980, 76, 163. (e) Hariharan, P. C.; Pople, J. A. Theo. Chim. Acta 1973, 28, 213.

(11) Schmidt, M. W.; Ruedenberg, K. J. Chem. Phys. 1979, 71, 3961.

(12) Gutowski, M.; Simons, J. J. Chem. Phys. 1990, 93, 3874.

(13) Our computed vertical detachment energy for $\mathrm{NH}_{4}{ }^{-}$is $0.463 \mathrm{eV}$, which compares to the experimental value ${ }^{2}$ of $0.4 \mathrm{eV}$. For $\left(\mathrm{NH}_{4}\right)_{2}{ }^{-}$, our computed vertical detachment energy is $0.461 \mathrm{eV}$.

(14) Complete information for the anion, in the form of the Cartesian coordinates of all atoms, is available by contacting the author. The geometries of the cation and neutral molecule can be found in the article by Boldyrev et al. in ref 3 .

(15) (a) Huber, K. P.; Herzberg, G. Constants of Diatomic Molecules; Van Nostrand Reinhold: New York, 1979. (b) Dixon, D. A.; Gole, J. L.; Jordan, K. D. J. Chem. Phys. 1977, 66, 567. (c) Sunil, K. K.; Jordan, K. D. Chem. Phys. Lett. 1984, 104, 343. In this reference and ref 16B, a good discussion is given about the nature of the bonding in alkali dimer anions and how it does not follow the nominal bond order. (d) Jones, K. M.; Maleki, S.; Bize, S.; Lett, P. D.; Williams, C. J.; Richling, H.; Knöckel, H.; Tiemann, E.; Wang, H.; Gould, P. L.; Stwalley, W. C. Phys. Rev. 1996, A54, R1006. (e) Stwalley, W. C. J. Chem. Phys. 1976, 65, 2038. (f) Zemke, W. T.; Stwalley, W. C. J. Phys. Chem. 1993, 97, 2053.

(16) Huber, K. P.; Herzberg, G. Constants of Diatomic Molecules; Van Nostrand Reinhold: New York, 1979. 